\title{
Long noncoding RNA network: Novel insight into hepatocellular carcinoma metastasis (Review)
}

\author{
XIUMING ZHU ${ }^{1,2}$, HONGMING PAN ${ }^{1}$ and LILI LIU ${ }^{1}$ \\ ${ }^{1}$ Department of Medical Oncology, Sir Run Run Shaw Hospital, School of Medicine, Zhejiang University, \\ Hangzhou, Zhejiang 310016; ${ }^{2}$ Department of Medical Oncology, Zhejiang Provincial People's Hospital \\ (People's Hospital of Hang Zhou Medical College), Hangzhou, Zhejiang 310014, P.R. China
}

Received September 20, 2020; Accepted April 16, 2021

DOI: $10.3892 /$ ijmm.2021.4967

\begin{abstract}
Hepatocellular carcinoma (HCC) is one of the most common, aggressive malignancies with poor prognosis and high mortality. Although great progress has been made in recent decades, overall survival of HCC patients remains unsatisfactory due to high recurrence and metastasis. Accordingly, understanding and clarifying the underlying molecular mechanisms of metastasis has become increasingly important. Recently, accumulated reports have supported that long noncoding RNAs (lncRNAs) are dysregulated in $\mathrm{HCC}$ and are involved in various pivotal biological processes, including metastasis. The aim of this review was to investigate the dysregulation of IncRNAs in HCC and their function as oncogenes or tumour suppressors. Furthermore, reciprocal regulatory networks between IncRNAs and various molecules that were identified in $\mathrm{HCC}$ metastasis, including regulating epithelial-mesenchymal transition (EMT), controlling metastasis-associated genes, and regulating tumour angiogenesis were examined. Numerous reports and information on lncRNAs may help identify lncRNAs that are potential novel diagnostic markers, prognostic markers and therapeutic targets.
\end{abstract}

\section{Contents}

1. Introduction

2. IncRNAs are aberrantly expressed in $\mathrm{HCC}$

3. IncRNAs and EMT

4. IncRNAs and HCC metastasis-associated genes

5. IncRNAs and angiogenesis

6. Conclusion and future perspectives

Correspondence to: Dr Hongming Pan or Dr Lili Liu, Department of Medical Oncology, Sir Run Run Shaw Hospital, School of Medicine, Zhejiang University, 3 East Qinchun Road, Hangzhou, Zhejiang 310016, P.R. China

E-mail: panhongming@zju.edu.cn

E-mail: liulili@zju.edu.cn; liulili8945@126.com

Key words: long noncoding RNA, hepatocellular carcinoma, metastasis, epithelial-mesenchymal transition, therapeutic targets

\section{Introduction}

Hepatocellular carcinoma (HCC) is one of the most common, aggressive malignancies and a frequent cause of cancer-related mortality worldwide, especially in many Asian and African countries $(1,2)$. The high recurrence rate of HCC is mainly due to the spread of intrahepatic metastasis $(3,4)$. Metastasis is a complex and multistep process. In this process, tumour metastasis-related gene abnormalities, epithelial-mesenchymal transition (EMT), and tumour microenvironment alterations, such as angiogenesis, are believed to be important for the metastasis process (5). However, the underlying molecular mechanisms that mediate the metastatic cascade remain unclear. Recently, accumulated evidence suggests that long noncoding RNAs (lncRNAs) may play a crucial role in the metastasis process of $\mathrm{HCC}$.

IncRNAs are defined as RNA molecules with a length of 200-100,000 bp that lack protein-coding potential $(6,7)$. lncRNAs have been reported to be involved in gene regulation, including transcriptional and post-transcriptional regulation, epigenetic regulation, and siRNA-directed gene regulation (8). Hundreds of lncRNAs have been identified (http://rfam.xfam. org) by computational predictions, and some of them have been experimentally verified and show tissue-specific expression (9-11). Moreover, these novel lncRNAs were elucidated to be involved in some pivotal biological processes, including cell growth, proliferation, apoptosis and metastasis and angiogenesis (12). In addition, recent evidence suggests that some HCC-related lncRNAs can act either as oncogenes or tumour suppressor genes, and expression profiling has revealed characteristic lncRNA signatures in HCC $(13,14)$. Similarly, some HCC-related IncRNAs have been suggested to be useful as novel potential markers for HCC diagnosis and prognosis (15). This review focused on the relationship between lncRNAs and EMT, HCC metastasis-related genes and tumour angiogenesis and highlights many pathways of lncRNAs involved in these processes.

\section{IncRNAs are aberrantly expressed in HCC}

Gene expression profiling analyses have shown that numerous lncRNAs are dysregulated in HCC cell lines or cancer tissues compared with liver normal cell lines or matched normal 
liver tissue $(16,17)$. Importantly, some of these aberrantly expressed lncRNAs have been confirmed to be associated with hepatocarcinogenesis $(18,19)$. In addition, lncRNA expression signatures were correlated with clinicopathological characteristics of HCC, such as metastasis and prognosis $(20,21)$. In the present review, the aberrant expression of IncRNAs and their biological roles in HCC were summarized (Table I).

Among the upregulated lncRNAs, highly upregulated in liver cancer (HULC) was identified and reported by more than one study. As Fig. 1A shows, HULC, as an oncogene, promotes tumorigenesis by controlling multiple pathways, such as upregulation of HMGA2 expression (13), promotion of EMT via miR-200a-3p (22), promotion of abnormal lipid metabolism via RXRA (23), and upregulation of sphingosine kinase 1 (SPHK1) expression to promote tumour angiogenesis (24). The reports indicated that these signalling pathways broadly interact with each other and highlight the complexity of gene regulation by lncRNAs. Interestingly, HULC was also upregulated in other cancer types, including gastric cancer, osteosarcoma, pancreatic cancer and breast cancer (25). The aforementioned studies suggested that HULC plays an important pathogenic role and clinical value in human cancer. Among the downregulated lncRNAs, as shown in Fig. 1B, maternally expressed gene 3 (MEG3), as a tumour suppressor, inhibits tumorigenesis and progression by regulating multiple pathways, such as the MEG3/miR-664/ADH4 (14) and DNMT1/MEG3/P53 axes (26,27). Taken together, these data indicate that dysregulation of lncRNAs results in abnormal expression of target genes and activity of signalling pathways, eventually leading to tumorigenesis and metastasis.

\section{IncRNAs and EMT}

Epithelial-mesenchymal transition. Epithelial-mesenchymal transition (EMT) is a highly conserved molecular reprogramming process that causes polarized immotile epithelial cells to change to motile mesenchymal cells (28). This process was initially recognized during embryonic development and was implicated in the early events of tumour cell metastasis by endowing cells with a more motile, invasive potential $(29,30)$. EMT is mediated by key transcription factors, including zinc-finger E-box-binding (ZEB), SNAIL, and basic helix-loop-helix (bHLH) transcription factors (31). These key transcription factors are regulated at the transcriptional and translational levels. In addition to EMT transcription factors, different signalling pathways have leading roles in the initiation and progression of EMT (32). Thus, IncRNAs may play a crucial role in EMT progression.

IncRNAs regulate EMT transcription factors and direct targets. lncRNAs that selectively bind mRNAs, miRNAs, and proteins, thus inhibiting their transcription, promoting their degradation or suppressing their translation, also regulate EMT progression $(6,33)$. A decrease in E-cadherin expression is considered a crucial step and fundamental event in the progression of EMT. We know that SNAIL and ZEB transcription factors, as EMT drivers, can bind to and repress the activity of the E-cadherin promoter, leading to EMT $(31,34)$. Accumulated evidence has shown that some lncRNAs control the expression of EMT master transcription factors. A schematic model and regulatory network of lncRNA functions during the process of EMT were summarized and generated (Fig. 2). For example, lncRNA-ATB and lncRNA HULC upregulated ZEB1 and ZEB2 expression by competitively binding miR-200a; hence, lncRNA-ATB and lncRNA HULC depletion or the loss of ZEB by siRNA can reverse EMT and inhibit HCC invasion and metastasis $(22,35)$. Additionally, lncRNA CCAT2, as an oncogene, promotes SNAIL2 and ZEB1 expression, and decreased expression of E-cadherin leads to EMT $(36,37)$. Interestingly, lncRNA CCAT2 can promote $\mathrm{HCC}$ progression by competitively binding to miR-34a and upregulating FOXM1 expression while FOXM1 binds to the CCAT2 promoter to activate its transcription, resulting in a double-positive feedback loop between CCAT2 and FOXM1 (38). SNHG20 promoted ZEB1/2 and N-cadherin expression and downregulated E-cadherin expression in $\mathrm{HCC}$ by binding to enhancer of zeste homolog 2 (39). A similar regulatory mechanism also exists between SPRY4-IT1 and EZH2 and E-cadherin (40).

UCA1 upregulation promotes the translation of SNAIL2 mRNA and induces EMT progression in HCC by effectively sponging miR-203. MiR-203 and SNAIL2 regulation is a double-negative feedback loop, with miR-203 suppressing SNAIL2 expression and SNAIL2 protein repressing the expression of miR-203 (41). During EMT, increased HULC or UBE2CP3 expression results in upregulation in SNAIL1 levels and EMT progression $(42,43)$. Additionally, lncRNA-MUF overexpression accelerated EMT progression by binding Annexin A 2 and activating the Wnt/ $\beta$-catenin pathway. lncRNA-MUF functions as a competing endogenous RNA for miR-34a, leading to SNAIL1 upregulation and EMT activation (44). Finally, SNAIL2, as a target of miR-140-5p (which induces EMT in HCC cells), is upregulated by Unigene 56159 in HCC (45).

Apart from regulating EMT transcription factor expression, lncRNAs target genes that encode adhesion junction and polarity complex proteins and signalling mediators. For example, high levels of lncRNA UBE2CP3, which are related to poor prognosis in HCC patients, inhibit E-cadherin expression but enhance SNAIL1 and $\mathrm{N}$-cadherin expression and promote EMT progression by increasing HCC cell invasion and migration (43). Similarly, high levels of PVT1 promote HCC cell EMT progression by repressing E-cadherin expression (46). Conversely, lncRNA-p21 inhibits HCC invasion and metastasis through the miR-9/E-cadherin cascade signalling pathway (47). $\mathrm{N}$-cadherin expression is repressed by SNHG20, the expression of which is positively associated with larger tumour size and is negatively correlated with OS in HCC patients. Additionally, decreased SNHG20 expression in HCC cells results in increased $\mathrm{N}$-cadherin expression levels and induces EMT progression (39). During EMT, high expression of ZEB2 AS1, which was correlated with tumour metastasis in HCC, enhanced HCC metastasis by regulating ZEB2, E-cadherin and N-cadherin expression (48).

Several lncRNAs could repress the expression of the intermediate filament protein vimentin, which changes the normal cytoskeleton structure, to inhibit HCC cell EMT progression and metastasis. Among these, lncRNA-Dreh, which is downregulated by $\mathrm{HBx}$, targets vimentin mRNA, resulting in decreased vimentin expression and reduced dissolution of tight 
Table I. Dysregulation of lncRNAs and biological function in HCC.

\begin{tabular}{|c|c|c|c|}
\hline $\operatorname{lncRNAs}$ & Dysregulation & Biological function in $\mathrm{HCC}$ & (Refs.) \\
\hline HULC & Upregulation & $\begin{array}{l}\text { Promote tumorigenesis and metastasis. Associated with HBV } \\
\text { infection. As a prognosis biomarker }\end{array}$ & $(10,13,18,20,22-25)$ \\
\hline MALAT1 & Upregulation & Promote HCC growth, motility, metastasis & $(69,70-73)$ \\
\hline HOTAIR & Upregulation & $\begin{array}{l}\text { Promote cell invasion, metastasis. As a diagnosis, recurrence and } \\
\text { prognosis biomarker }\end{array}$ & $(64-66)$ \\
\hline HOTTIP & Upregulation & $\begin{array}{l}\text { Promote tumorigenesis and progression. Associated with disease } \\
\text { outcome }\end{array}$ & $(21)$ \\
\hline HEIH & Upregulation & $\begin{array}{l}\text { Associated with HBV-related HCC. As a recurrence and prognosis } \\
\text { biomarker }\end{array}$ & $(42)$ \\
\hline PCAT-1 & Upregulation & $\begin{array}{l}\text { Promote cell proliferation and invasion, metastasis. Associated with } \\
\text { prognosis }\end{array}$ & (80) \\
\hline PVT1 & Upregulation & Promote cell proliferation, cell cycling. Associated with prognosis & $(46)$ \\
\hline ATB & Upregulation & Promote HCC metastasis & $(35)$ \\
\hline CCAT1 & Upregulation & Promote cell proliferation and migration & $(78)$ \\
\hline CCAT2 & Upregulation & $\begin{array}{l}\text { Regulate cell proliferation, migration, apoptosis, metastasis, } \\
\text { associated with prognosis }\end{array}$ & $(36-38)$ \\
\hline SNHG20 & Upregulation & Promote cell invasion. Associated with prognosis & $(39)$ \\
\hline SPRY4-IT1 & Upregulation & Promote cell proliferation and invasion. As a diagnosis biomarker & $(40)$ \\
\hline UCA1 & Upregulation & Promote HCC growth, metastasis and associated with prognosis & $(41)$ \\
\hline TCF7 & Upregulation & Promote HCC progression by EMT and Wnt signaling & $(62)$ \\
\hline ZFAS 1 & Upregulation & $\begin{array}{l}\text { Associated with intrahepatic and extrahepatic metastasis and poor } \\
\text { prognosis of HCC }\end{array}$ & $(61)$ \\
\hline ZEB1-AS1 & Upregulation & Promote HCC metastasis and predict poor prognosis & (79) \\
\hline ZEB2-AS1 & Upregulation & Promote tumor growth and metastasis. Associated with prognosis & $(48)$ \\
\hline MVIH & Upregulation & $\begin{array}{l}\text { Promote HCC growth and intrahepatic metastasis, associated with } \\
\text { prognosis }\end{array}$ & (78) \\
\hline MEG3 & Downregulation & Inhibit cell proliferation. Associated with prognosis and methylation & $(14,26,27,99,100)$ \\
\hline lncRNA-P21 & Downregulation & Inhibit $\mathrm{HCC}$ cell invasion and metastasis & $(47,60)$ \\
\hline CPS1-IT1 & Downregulation & Inhibit HCC metastasis & $(63)$ \\
\hline GAS5 & Downregulation & Associated with prognosis, suppress cell proliferation and invasion & $(51,82-84)$ \\
\hline XIST & Downregulation & Inhibit HCC cell proliferation and metastasis & $(87-92)$ \\
\hline lncRNA-LET & Downregulation & As a regulator of hypoxia signaling, inhibit HCC invasion & $(81,107)$ \\
\hline FTX & Downregulation & Inhibit cell proliferation and metastasis. Promote cell proliferation & $(85,86)$ \\
\hline
\end{tabular}

junctions, to block EMT (49). Vimentin is also controlled by IncRNA AOC4P and lncRNA GAS5, both of which are tumour suppressors that bind to vimentin and promote its degradation and therefore inhibit HCC invasion and metastasis $(50,51)$. Additionally, CASC2 could inhibit HCC cell invasion and EMT progression by targeting the miR-367/FBXW7 axis, and lncRNA-p21 decreased EMT and metastasis by targeting Notch (52). Clearly, abnormal expression and activities of IncRNAs represent an extensive regulatory network by changing the gene expression programme to control EMT progression.

lncRNAs mediate control of EMT signalling pathways. Long noncoding RNAs are commonly known as potential gene expression modifiers that alter several phases of expression, including transcription, post-transcriptional processing, translation, and epigenetic regulation (6). Recently, the number of known lncRNAs that have been directly or indirectly associated with EMT signalling pathways has become extensive (Fig. 3). Multiple signalling pathways trigger EMT in the initiation and progression of tumour metastasis, including the transforming growth factor- $\beta$ (TGF- $\beta$ ) family, Wnt $/ \beta$-catenin, Notch, EGF, HGF, FGF, and HIF. Among these pathways, the TGF- $\beta$ signalling pathway has a predominant role, but the others are also required. Most importantly, the convergence of these signalling pathways is essential for EMT (53).

As the role of TGF- $\beta$-induced EMT in cancer cell dissemination is well established, Yuan et al reported that IncRNA-ATB promotes HCC cell metastasis by competitively binding miR-200a, upregulating ZEB1 and ZEB2, and then inducing EMT (35). Notably, several similar reports in other tumour types (lung cancer, breast cancer and endometrial carcinoma) have been reported. For example, Li et al showed that MALAT1 expression was increased by TGF- $\beta$ induction, 
A

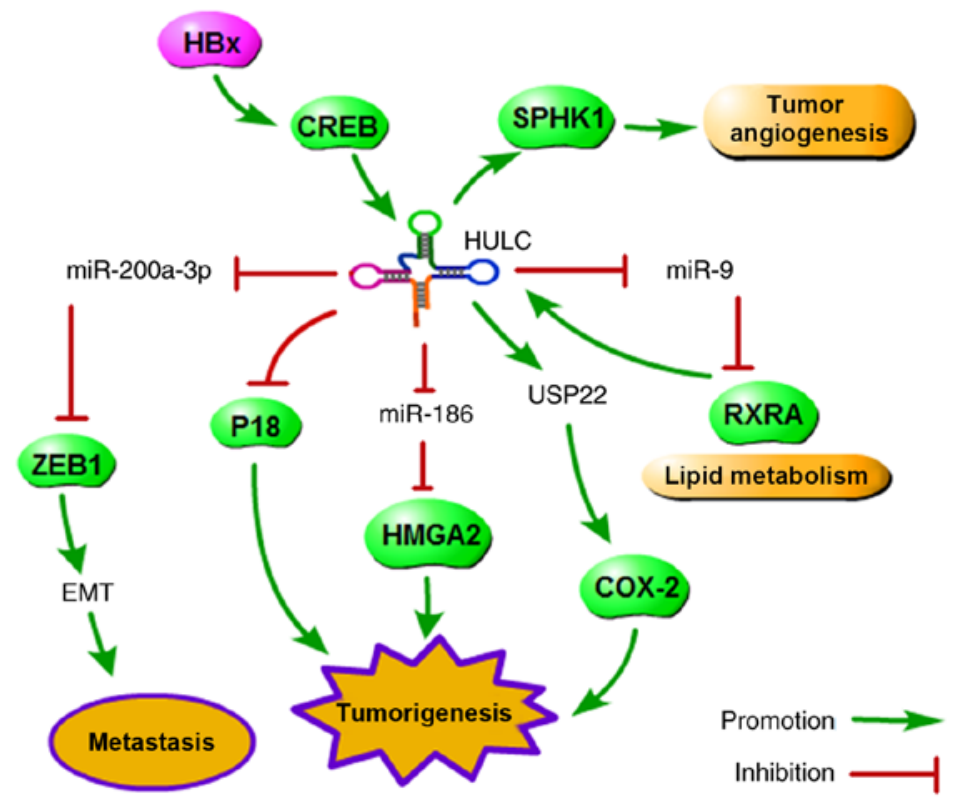

B

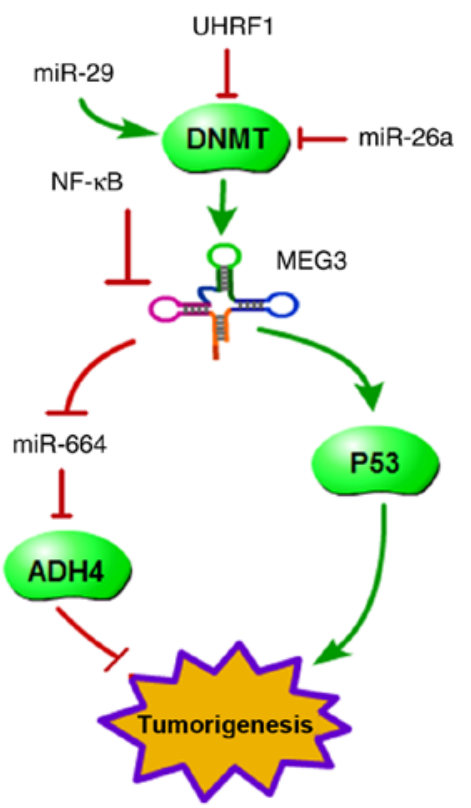

Figure 1. IncRNAs are aberrantly expressed in HCC. (A) HULC, which is upregulated in HCC, promotes tumorigenesis by controlling some pathways, such as upregulation of HMGA2, promotion of EMT via miR-200a-3p, promotion of abnormal lipid metabolism via RXRA and upregulation of SPHK1 to promote tumour angiogenesis. (B) MEG3, which is downregulated in HCC, inhibits tumorigenesis by regulating some pathways, such as the MEG3/miR-664/ADH4 and DNMT1/MEG3/P53 signalling axes. HCC, hepatocellular carcinoma; HULC, highly upregulated in liver cancer.

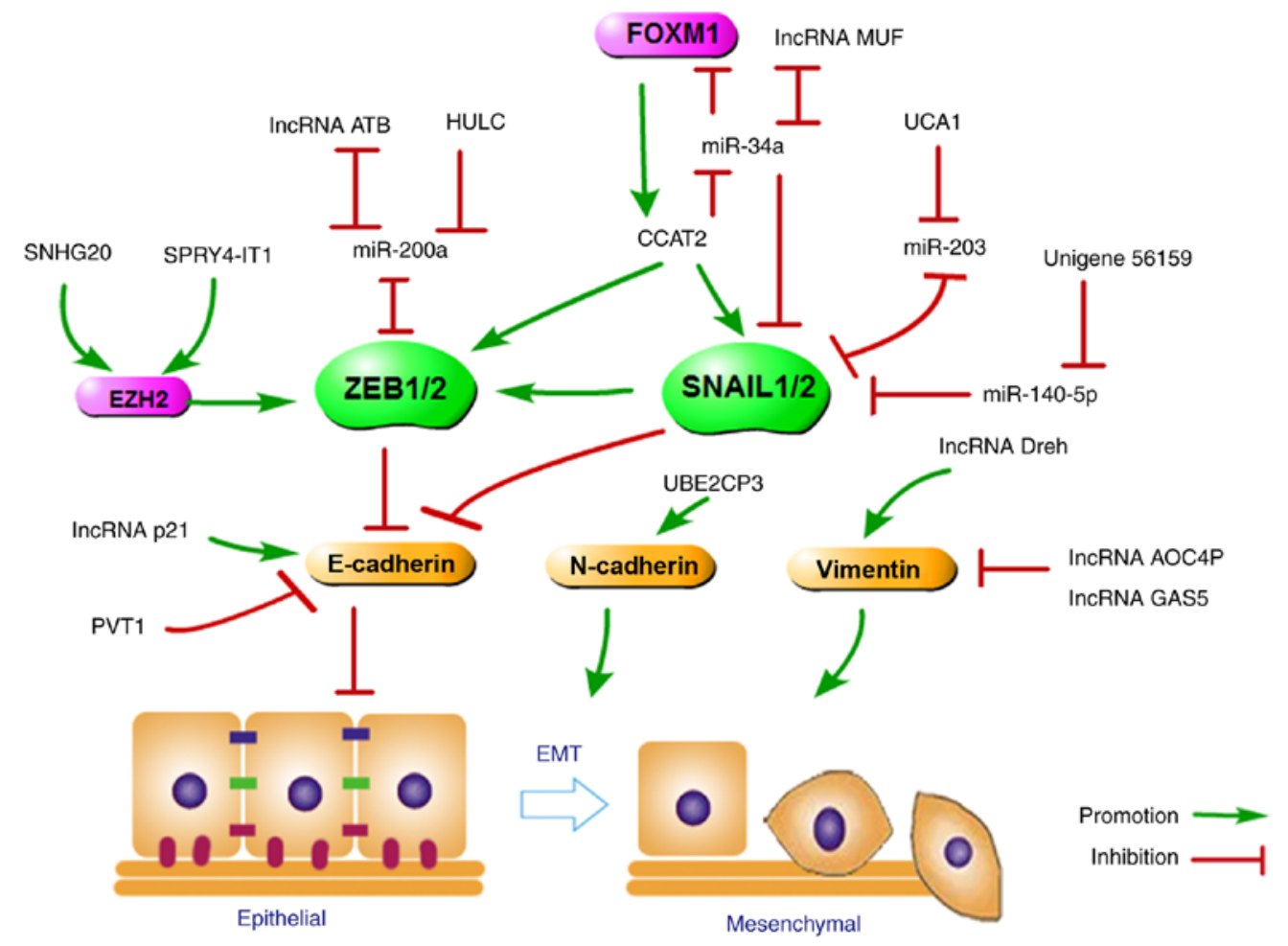

Figure 2. IncRNAs regulating EMT transcription factors and direct targets. A schematic model and regulatory network of lncRNA functions during the process of EMT are summarized. SNAIL1/2 and ZEB1/2 are EMT-related transcription factors, and E-cadherin, Vimentin and N-cadherin are direct EMT targets. Dysregulation of lncRNAs may lead to EMT progression by affecting EMT transcription factors or direct targets. For example, lncRNA-ATB and lncRNA HULC upregulated ZEB1/2 expression by competitively binding miR-200a, whereas IncRNA CCAT2 promoted SNAIL2 and ZEB1 expression, and decreased the expression of E-cadherin, leading to EMT.

and the miR-200c/MALAT1 axis could inhibit the expression of EMT-associated proteins in endometrial carcinoma (EEC) and subsequently repress EMT progression. Once the interaction between miR-200c/MALAT1 was interrupted, EMT marker expression was altered, and the TGF- $\beta$ signalling pathway was activated (54). Findings of a previous study 


\section{IncRNAs mediated control of EMT signaling pathway}

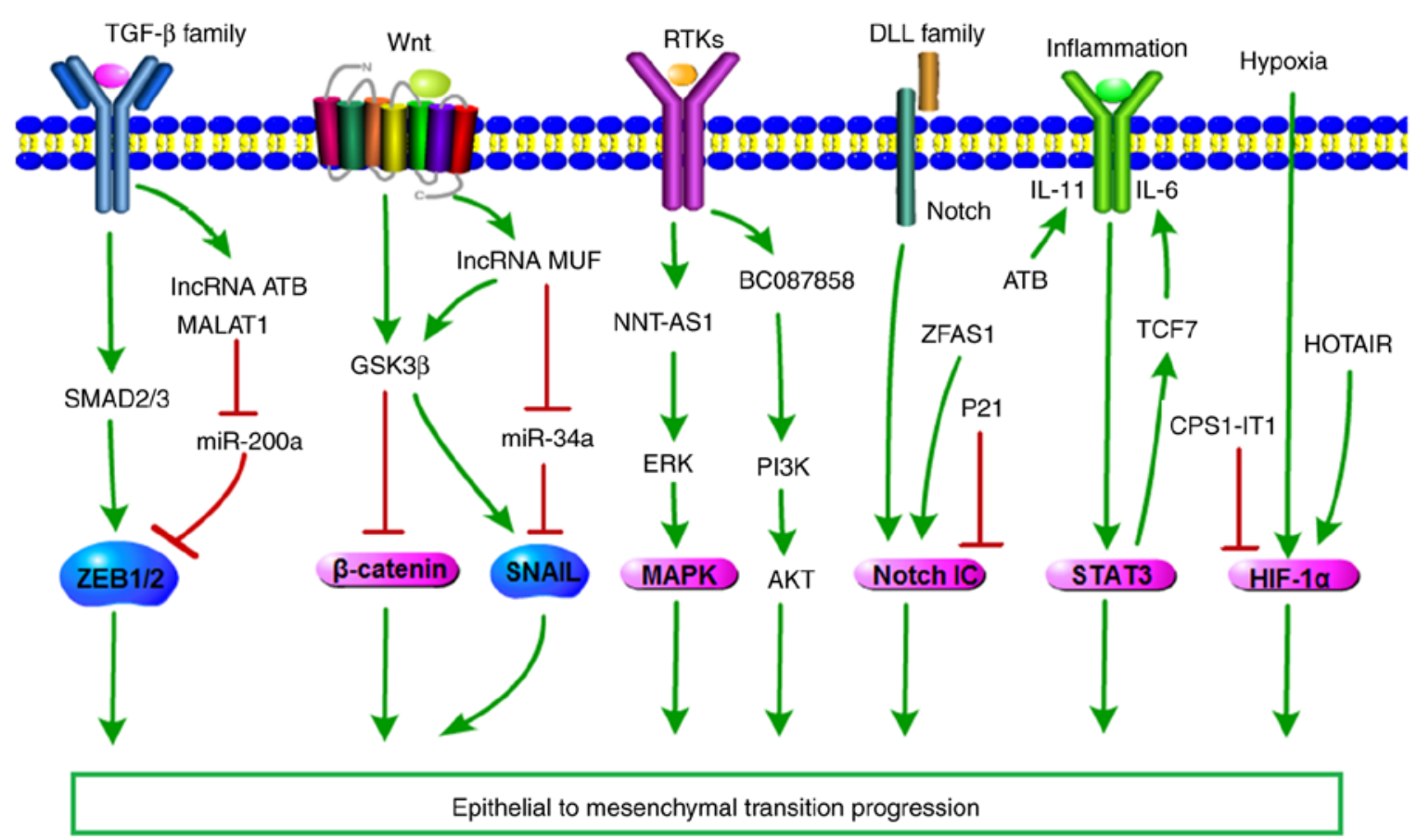

Figure 3. lncRNA-mediated control of EMT signalling pathways. Schematic representation of lncRNAs that are deregulated in human hepatocellular carcinoma-mediated control of EMT signalling pathways. TGF- $\beta$, Wnt/ $\beta$-catenin, PI3K, and Notch signalling pathways affected by the upregulated lncRNAs ATB, MALAT1, lncRNA MUF, BC087858 and HOTAIR or the downregulated lncRNAs P21 and CPS1-IT1 may lead to EMT progression.

showed that, lnc00673 activated by TGF- $\beta$ induced EMT, promoted lung cancer cell invasion by inhibiting miR-150-5p expression, and then upregulated ZEB1 to finally induce EMT progression (55). Additionally, studies with similar regulatory mechanisms were also reported $(56,57)$.

The WNT signalling pathway promotes EMT, and $\beta$-catenin-mediated gene expression is increased in tumour cells and tissues. IncRNA-MUF is highly expressed in HCC. Decreased IncRNA-MUF expression repressed EMT; conversely, IncRNA-MUF overexpression accelerated EMT progression. Mechanistic investigations suggested that IncRNA-MUF combined with Annexin A2 to activate Wnt/ $\beta$-catenin and EMT. In addition, lncRNA-MUF can bind to miR-34a, leading to Snaill upregulation and EMT activation (44).

The activation of EMT by receptor tyrosine kinases (RTKs) highlights the roles of the PI3K-AKT and MAPK pathways in this transitional process. MAPK pathway activation by not only growth factors but also mutations in the genes encoding RAS or RAF, also contributes to EMT. IncRNA NNT-AS1 promoted CRC cell migration and invasion by activating the ERK/MAPK pathway and EMT (58). IncRNA BC087858 could promote cell invasion by activating the PI3K/AKT and MEK/ERK pathways and EMT by upregulating ZEB1 and Snail expression in NSCLC (59).

The Notch signalling pathway also triggers EMT. Overexpression of lincRNA-p21 inhibited Notch signalling and EMT, while its downregulation led to the reverse result (60). Upregulation of ZFAS1 expression in glioma tissues was significantly associated with poor overall survival. EMT and the Notch signalling pathway were inhibited in glioma cells after ZFAS1 knockdown. Therefore, ZFAS1 could exhibit an oncogenic role by regulating EMT and the Notch signalling pathway (61).

Activation of the HIF- $\alpha$ /STAT3 signalling pathway also switches on the EMT process. IncRNA-ATB promoted the colonization of disseminated tumour cells to organs by binding IL-11 and triggering STAT3 signalling (35). IL- 6 could induce lncTCF7 expression in HCC cells by activating STAT3. Importantly, knocking down STAT3 and repressing STAT3 activation reduced lncTCF7 expression; as a result, decreased lncTCF7 prevented IL-6-induced EMT (62). Decreased expression of CPS1-IT1 was significantly correlated with poor prognosis. CPS1-IT1 acts as a tumour suppressor in HCC by decreasing HIF-1 $\alpha$ activation and inhibiting the EMT process (63). Another report describes HOTAIR and RCC metastasis. The results showed that HOTAIR promotes RCC tumorigenesis and metastasis via miR-217/HIF-1 $\alpha / \mathrm{AXL}$ signalling both in vitro and in vivo (64).

Clearly, these intricate networks are closely connected, and changes in any of these networks have a profound effect on other networks. Once the network of balance is disrupted, one or several signalling pathways may be switched on and activated, finally leading to EMT or MET.

\section{IncRNAs and HCC metastasis-associated genes}

The role of lncRNAs either as oncogenes or tumour suppressors. The role of lncRNAs either as oncogenes or 
tumour suppressors in human cancers, including HCC, has been previously established. Genome-wide transcriptomic analyses have identified a series of metastasis-associated genes, and their aberrant expression in primary HCC correlates with metastasis and poor prognosis. Recently, an increasing number of lncRNAs associated with metastasis based on lncRNA profiling of early-stage versus advanced HCC tissues have been identified and verified as upstream regulators of metastasis-associated genes. For the present review, the available evidence on these lncRNAs in HCC was summarized.

Pro-metastatic lncRNAs regulate HCC invasion and metastasis. High expression of HOX transcript antisense RNA (HOTAIR) in human breast cancer was first reported by Gupta et al (65). Overexpression of HOTAIR promoted cancer cell metastasis in vitro and in vivo. Following investigation of the mechanism, they reported that HOTAIR is selectively required to target polycomb repressive complex 2 (PRC2) and induce methylation of histone H3 on lysine 27 (H3K27me3), resulting in the downregulation of multiple metastasis suppressor genes, including HOXD10 and many others. Moreover, HOTAIR is highly expressed in breast cancer tissues, and upregulation of HOTAIR expression in primary breast cancer is a powerful predictor of prognosis (65). Similarly, HOTAIR is correlated with tumour size and lymph node metastasis in HCC. Knockdown of HOTAIR decreases matrix metallopeptidase-9 (MMP-9) and vascular endothelial growth factor (VEGF) expression, which play an important role in metastasis (66). The HOTAIR/PRC2/H3K27me3/HOXD axis is a classic example of metastasis-related interplay between IncRNAs and cancer metastasis-associated genes.

As described previously, HOXD may be a key lncRNA in the cancer metastatic pathway. IncRNA HOXD-AS1 is transcribed in the antisense orientation of the protein-coding gene HOXD1. IncRNA HOXD-AS1 functions as an oncogene and can promote cell invasion and metastasis by affecting signalling pathways in various cancer cell lines. Global gene expression analysis revealed that HOXD-AS1 upregulation was associated with poor prognosis in HCC patients and may represent an independent prognostic biomarker in HCC. Mechanistically, the transcription factor STAT3 could activate the transcription of HOXD-AS1, which protects SOX4 against miRNA-mediated degradation and thus activates the expression of EZH2 and MMP2 to facilitate HCC metastasis (67). Lu et al reported that HOXD-AS1 promotes HCC metastasis and that its pro-metastatic phenotype can partially be attributed to the HOXD-AS1/miR-19a/ARHGAP11A signalling axis (68). Accordingly, the HOTAIR/PRC2/H3K27me3/HOXD, HOXD-AS1/miR-130a-3p/SOX4/EZH2 and MMP2 and HOXD-AS1/miR-19a/ARHGAP11A signalling pathways form a cascade effect for HCC metastasis (Fig. 4).

Yuan et al found that upregulated expression of lncRNA-activated by TGF- $\beta$ (IncRNA-ATB) in HCC could induce EMT and promote the invasion-metastasis cascade of HCC cells in vivo. Mechanistically, they reported that lncRNA-ATB promotes HCC metastasis by functioning as a ceRNA for the miR-200 family that targets ZEB1 and ZEB2, which induces EMT. The miR-200 family regulates EMT by targeting ZEB1 and ZEB2, and EMT facilitates tumour invasion and dissemination. However, Yuan and colleagues (35) also found that lncRNA-ATB promoted HCC cell metastasis, which was not completely dependent on the miR-200 family. This suggested that metastasis is determined not only by the miR-200-ZEB-EMT axis, but also by an additional downstream player of IncRNA-ATB. Indeed, IncRNA-ATB promotes HCC cell colonization by binding IL-11, causing autocrine induction of IL-11 secretion and consequent activation of STAT3 signalling (35). Thus, lncRNA-ATB plays a pro-metastatic role in HCC. The expression of lncRNA-ATB was increased in HCC, breast cancer, colorectal cancer and gastric cancer cell lines. Accordingly, activity of the lncRNA-ATB/miR-200/ZEB and lncRNA-ATB/IL-11/STAT3 pathways finally leads to HCC tumorigenesis and metastasis.

The long noncoding RNA metastasis-associated lung adenocarcinoma transcript 1 (MALAT1), the expression of which is upregulated in lung cancer tissues and cells, is a critical regulator of the metastasis phenotype of lung cancer (9). Similarly, findings have shown that MALAT1 is a pro-metastatic lncRNA in HCC invasion and metastasis. First, the level of MALAT1 expression correlated significantly with advanced clinical stage, metastasis and poor prognosis in HCC. Moreover, MALAT1 was found to promote HCC cell invasion and metastasis both in vitro and in vivo (69). In addition, many targets of MALAT1, which include some metastasis-associated genes that directly or indirectly regulate HCC metastasis, have been identified by computational predictions, and some of them have been experimentally verified (Fig. 5). Transforming growth factor $\beta$-binding protein 3 (LTBP3), which has been identified as a target gene of MALAT1, could promote HCC cell migration and invasion, which could also be upregulated by HBx. Mechanistically, one group found that HBx could upregulate MALAT1 and that MALAT1 could further activate the expression of LTBP3, resulting in the promotion of HCC metastasis (70). EGFR is also an important target of MALAT1, not only because EGFR is a validated driver gene and an important protein in tumour metastasis, but also because EGFR can promote the PI3K/AKT and JAK/STAT signalling pathway activity. Mechanistically, MALAT promotes HCC metastasis by targeting miR-195-mediated EGFR phosphorylation (71). Similar to EGFR, ZEB1 and TRAF6 (as targets of MALAT1 mediated by miR-143-3p and miR-146-5p) promote HCC metastasis $(72,73)$. Aside from its role in regulating downstream genes, MALAT1 is regulated by several tumour metastasis-associated genes. TGF- $\beta, \mathrm{c}-\mathrm{MYC}$, and HIF- $2 \alpha$ could induce or activate the expression of MALAT1 by different molecular mechanisms (74-76). With the reciprocal positive feedback loop between MALAT1 and EZH2 or HIF-2 $\alpha$, these upstream regulators and downstream targets, such as EGFR, ZEB1, LEBP3 and TRAF6, compose a complex network to regulate $\mathrm{HCC}$ metastasis.

Recently, several other IncRNAs were proposed to promote $\mathrm{HCC}$ growth and metastasis. Yang et al reported that a high lncRNA expression in HCC was significantly associated with recurrence and is an independent prognostic factor for survival. lncRNA-HEIH promotes HCC growth by targeting enhancer of zeste homolog 2 (EZH2) (77). Moreover, lncRNA-MVIH (lncRNA associated with microvascular invasion in HCC) can also regulate HCC growth and intrahepatic metastasis by inhibiting the secretion of phosphoglycerate kinase 1 (PGK1). 


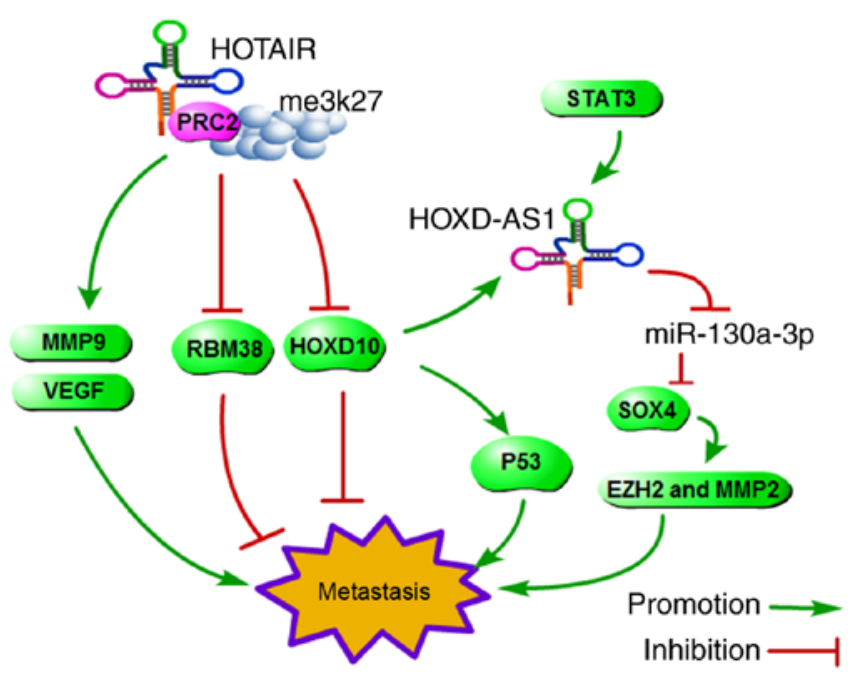

Figure 4. A schematic model and regulatory network of lncRNAs promoting HCC invasion and metastasis. The HOTAIR/PRC2/H3K27me3/HOXD, HOXD-AS1/miR-130a-3p/SOX4/EZH2, MMP2 and HOXD-AS1/miR-19a/ ARHGAP11A signalling pathways form a cascade effect for HCC metastasis.

CCAT1 promotes HCC progression by functioning as a let-7 sponge and leads to release of the repression of its endogenous targets HMGA2 and c-Myc (78). Another pro-metastatic lncRNA, ZEB1-AS1, is frequently upregulated in HCC, especially in metastatic HCC tissues. ZEB1-AS1 acts as an oncogene in HCC and promotes tumour growth and metastasis by positively regulating ZEB1 expression (79). PCAT-1 can promote $\mathrm{HCC}$ cell proliferation and viability by targeting the kinase CRK-like proto-oncogene adaptor protein (CRKL), and, in turn, PCAT-1 is regulated by miR-215, a P53-inducible miRNA. Therefore, the TP53-PCAT-1-CRKL axis may be an important regulatory pathway in HCC (80). Taken together, the data regarding these pro-metastatic lncRNAs and their targets suggest the existence of a complex network controlling HCC growth and metastasis.

Anti-metastatic lncRNAs regulate HCC invasion and metastasis. Yang et al (81) showed that lncRNA low expression in tumour (lncRNA-LET) was downregulated in HCC and confirmed it as a positive regulator of HCC metastasis. Those authors reported that hypoxia-induced histone deacetylase 3 (HDAC3) expression inhibits lncRNA-LET by decreasing the histone acetylation-mediated regulation of the IncRNA-LET promoter region. Then, IncRNA-LET was bound to target gene-nuclear factor 90 protein (NF90), which increases NF90 degradation by the proteasome. Finally, low IncRNA-LET expression contributes to hypoxia-induced HCC cell invasion (81).

Another metastasis suppressor, 1ncRNA GAS5, was found to be downregulated in HCC tissues compared to adjacent normal tissues. Moreover, a decreased expression of GAS5 was significantly correlated with differentiation and portal vein tumour metastasis and was an independent predictor for overall survival. In addition, it was demonstrated that GAS5 suppressed proliferation and invasion in HCC by negatively regulating vimentin expression (51). GAS5 was downregulated in other cancers, and restoring its expression significantly inhibited cancer progression. EZH2, miR-21

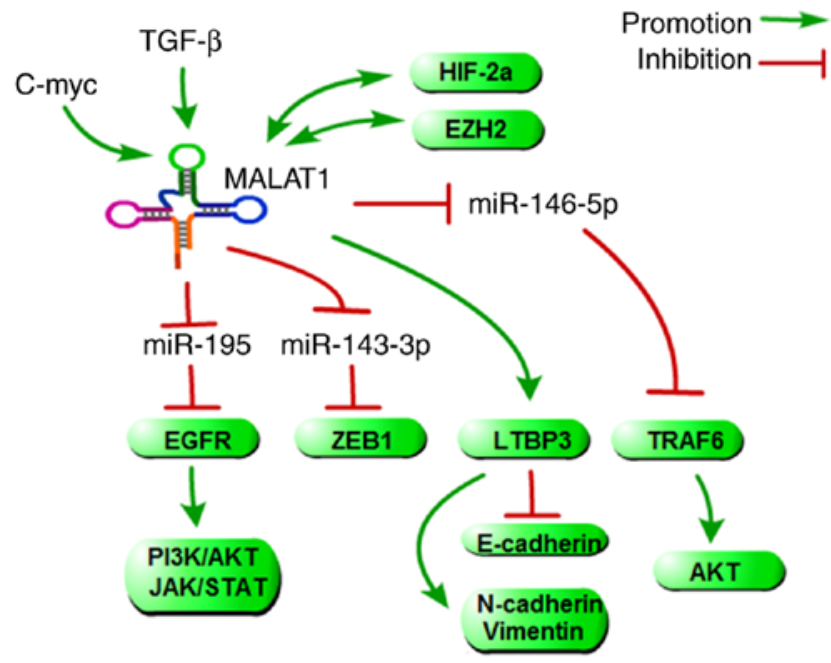

Figure 5. A schematic model of MALAT promoting HCC metastasis by targeting multiple genes. 1ncRNAs MALAT1 and EZH2 or HIF-2 $\alpha$, as upstream regulators, and their downstream targets, including EGFR, ZEB1, LEBP3 and TRAF6, compose a delicate network to regulate HCC metastasis.

and miR-222 were further verified as GAS5 target genes, and knocking down these genes can reduce the in vitro invasive ability and in vivo metastatic potential (82-84). The downregulation of long noncoding RNA FTX (lnc-FTX) was also found in HCC. Lnc-FTX can inhibit HCC cell epithelial-mesenchymal transition and invasion by physically binding miR-374a and MCM2 (85). Of note, Furlan et al reported that lnc-FTX is required in cis to promote XIST transcriptional activation and establishment of $\mathrm{X}$ chromosome inactivation (XCI) (86).

The long noncoding RNA XIST downregulation in HCC was first reported by Zhuang et al. They stated that XIST is one of the tumour suppressing lncRNAs that can inhibit HCC cell proliferation and metastasis. XIST and its target miR-92b directly interacted with and repressed each other (87). Similar results have also been reported: miR-181a and miR-194-5p promoted HCC progression by targeting PTEN and MAPK1, and both were mediated by the long noncoding RNA XIST $(88,89)$. Moreover, a decrease in the expression of long noncoding RNA XIST is associated with the prognosis of HCC. These results suggest that lncRNA XIST functions as a tumour suppressor to inhibit oncogene expression in hepatocellular carcinoma. Notably, lncRNA XIST has also been found to be dysregulated in other cancers, such as gastric (90), colorectal (91), and oesophageal cancer (92). However, those reports showed that XIST expression was upregulated in these cancers and functions as an oncogene. For example, Chen et al (91) reported that lncRNA XIST was overexpressed in colorectal cancer and that upregulation of lncRNA XIST was correlated with poor overall survival in CRC patients. lncRNA XIST promotes metastasis and modulates EMT in colorectal cancer by competing for miR-200b to regulate ZEB1 expression. Other research has shown that XIST promotes oesophageal squamous cell carcinoma by regulating miR-101/EZH2 (92). In addition, XIST was found to promote cell invasion by regulating the miR-497/MACC1 axis in gastric cancer and was associated with the prognosis of these patients (90). Consequently, XIST, miRNAs and oncogenes 


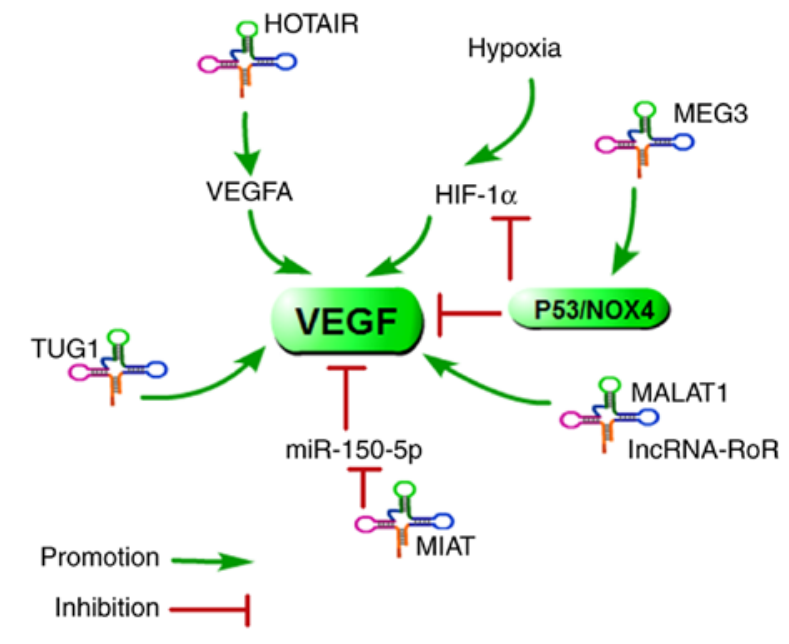

Figure 6. A schematic model of lncRNAs dysregulated in HCC affecting HCC angiogenesis by regulating VEGF or HIF-1A. Aberrantly expressed lncRNAs may affect cancer-associated angiogenesis. For example, upregulation of HOTAIR promoted tumour angiogenesis by directly activating VEGFA and Ang2 expression.

or tumour suppressors interact to create a large regulatory network. Once one of the genes was disrupted, the levels of the associated genes were changed; therefore, the entire network was broken.

\section{IncRNAs and angiogenesis}

Tumour angiogenesis is considered a crucial step and one of the cornerstones for helping to sustain expanding neoplastic growth (5). In this regard, HCC is one of the most vascular solid tumours with a high tendency for vascular invasion (93). A compelling body of evidence indicates that the angiogenesis switch is triggered by cellular stress factors such as hypoxia, the activation of oncogenes such as RAS and C-MYC or the inactivation of tumour suppressors, such as P53. One of the well-known regulatory pathways of angiogenesis is via signalling proteins that bind to cell-surface receptors demonstrated by vascular endothelial cells, such as VEGF and FGF (94). VEGF gene expression is induced and upregulated by hypoxia through hypoxia inducible factor-1 (HIF-1), which in turn activates VEGFR2 to stimulate cell migration and to initiate angiogenesis. The role of VEGF in the formation and development of neovascularization in HCC has been extensively reported and established in the process between the early and advanced stage of HCC. Furthermore, VEGF correlates with HCC progression, metastasis, a tendency towards portal invasion and a higher recurrence rate (95). Moreover, current clinical practice shows extensively established and accepted VEGFR-targeted therapies for patients with advanced HCC, such as the multi-kinase inhibitor sorafenib, which is well known to inhibit the kinase activities of VEGFR and PDGFR (96).

Recently, accumulating evidence has shown that aberrantly expressed lncRNAs could be linked to cancer-associated angiogenesis (Fig. 6). Fu et al reported that the upregulation of HOTAIR promoted tumour cell growth and angiogenesis by directly activating VEGFA and Ang2 expression (97). A similar result was also reported: HOTAIR could enhance angiogenesis by inducing VEGFA expression in glioma cells (98). Su et al found that MEG3 was downregulated and inversely associated with VEGF expression levels in osteoarthritis (99). Therefore, HOTAIR and MEG3 may play a major role in the control of angiogenesis. Next, a report demonstrated that MEG3 could regulate angiogenesis through activation of the p53/NOX4 axis, which would downregulate HIF-1 $\alpha$ and VEGF expression (100). Furthermore, upregulation of lncRNA TUG1 in hepatoblastoma promotes tumour growth and angiogenesis by enhancing the expression of VEGFA, which is regulated by miR-34a-5p (101). IncRNA-MIAT was able to promote endothelial cell proliferation, migration, and tube formation by increasing the expression of VEGF via direct binding to miR-150-5p (102). Additionally, a previous report indicated that MALAT1 could promote angiogenesis and immunosuppressive properties of mesenchymal stem cells by inducing VEGF and IDO expression (103). Zhu et al demonstrated that HULC could promote angiogenesis in human gliomas by regulating ESM-1 via the PI3K/Akt/mTOR signalling pathway (104). Furthermore, lncRNA associated with microvascular invasion in hepatocellular carcinoma (lncRNA MVIH) is well known to play an important role in $\mathrm{HCC}$ by inducing angiogenesis. IncRNA MVIH could activate tumour-inducing angiogenesis by repressing the secretion of PKG1 and increasing microvessel density in hepatocellular carcinoma (78).

Another well-known switch of angiogenesis is hypoxia. Under hypoxic conditions, angiogenesis can be activated by a family of transcription factors known as hypoxia inducible factors (HIFs), such as HIF-1. Dysregulation of HIF-1 expression is associated with tumour metastasis and poor clinical outcome in HCC (105). In recent years, a series of hypoxia-induced lncRNAs, such as HOTAIR, MALAT1, and PVT1, have been identified using RNA expression profiling and high-throughput approaches. Based on RNA expression profiling data, Takahashi et al identified 89 differentially expressed lncRNAs in HepG2 HCC cells under hypoxic conditions; 20 lncRNAs were upregulated by at least a 2-fold change, while 11 were downregulated under hypoxic conditions. Those authors further confirmed that lncRNA-RoR, as an oncogene, could drive tumour growth via the lncRNA-RoR/miR-145/HIF-1 $\alpha$ axis. These hypoxia-induced lncRNAs have important functions in controlling tumour phenotypes, such as angiogenesis (106).

Accumulating evidence has shown that several hypoxia-induced lncRNAs regulate tumour angiogenesis and metastasis by modulating the HIF-1 $\alpha$ signalling pathway. For example, Yang et al reported that lncRNA low expression in tumour (lncRNA-LET) was downregulated in hepatocellular carcinomas. Mechanistically, lncRNA-LET is suppressed under hypoxic conditions due to the activation of histone deacetylase 3 (HDAC3). IncRNA-LET was able to interact with nuclear factor 90 (NF90), which led to the degradation of NF90, therefore increasing HIF-1A under hypoxic conditions and leading to hypoxia-induced cancer cell invasion. Notably, lncRNA-LET downregulation was significantly correlated with tumour micrometastases in HCC (81). A similar result for lncRNA-LET as a prognostic marker for metastasis was also reported in primary gallbladder cancer (107). Another report showed that 
IncRNA-RERT downregulation was significantly correlated with HCC occurrence. IncRNA-RERT decreased the expression of HIF-1 $\alpha$ by upregulating EGLN2 mRNA levels (108). In addition, two other IncRNAs, HIF1A-AS1 and HIF1A-AS2, which are antisense transcripts transcribed from the 3'-UTR of the sense HIF-1A mRNA negatively regulated HIF1A mRNA expression $(109,110)$. Therefore, the association between HIF-1A mRNA levels and HIF1A-AS exhibits a negative feedback loop.

It has been well established that IncRNAs involved in the biological processes of HCC angiogenesis interact with the key angiogenesis regulators VEGF and HIF-1A and appear to be promising targets for anti-angiogenesis therapy. More novel lncRNA-associated angiogenesis and its mechanisms need to be identified and elucidated. Understanding the networks of interactions between IncRNAs and target genes may pave the way for new therapeutic strategies.

\section{Conclusion and future perspectives}

In this review, we have shown that, IncRNAs, acting as tumour suppressor genes or oncogenes, play an important role in HCC tumorigenesis and metastasis. Based on the corresponding relationships between IncRNAs, miRNAs and mRNAs, the regulatory relationships between IncRNAs and EMT, IncRNAs and HCC metastasis-related genes, lncRNAs and tumour angiogenesis were summarized. In these regulatory networks, once one of the important lncRNAs is out of balance, a chain reaction ultimately affects the relationship between multiple lncRNAs and several target genes of different pathways. Accordingly, with the identification of new lncRNAs associated with HCC metastasis, this regulatory network becomes increasingly complex. However, the molecular mechanism of HCC metastasis remains to be revealed more thoroughly. Based on current studies and additional lncRNAs that will be identified and verified in the future, lncRNAs may serve as novel diagnostic markers, prognostic markers and therapeutic targets.

\section{Acknowledgements}

Not applicable.

\section{Funding}

This review was supported by the Science and Technology Project of Zhejiang Province (2016KYA023, 2013RCA006, 2016ZA025, 2018KY466), the Natural Science Foundation of Zhejiang Province (LQ18H160025) and the National Natural Science Foundation of China (81572592).

\section{Availability of data and materials}

Not applicable.

\section{Authors' contributions}

LL and HP conceived the review. XZ and LL were involved in collecting the references, writing and reviewing the manuscript. XZ and LL were responsible for confirming the authenticity of all the raw data. The authors contributed to the final version.

\section{Ethics approval and consent to participate}

Not applicable.

\section{Patient consent for publication}

All authors consent to publication.

\section{Competing interests}

The authors declare that they have no competing interests.

\section{References}

1. Torre LA, Bray F, Siegel RL, Ferlay J, Lortet-Tieulent J and Jemal A: Global cancer statistics, 2012. CA Cancer J Clin 65: 87-108, 2015.

2. El-Serag HB: Epidemiology of viral hepatitis and hepatocellular carcinoma. Gastroenterology 142: 1264-1273, 2012.

3 . Forner A, Llovet JM and Bruix J: Hepatocellular carcinoma. Lancet 379: 1245-1255, 2012.

4. Bruix J and Sherman M; American Association for the Study of Liver Diseases: Management of hepatocellular carcinoma: An update. Hepatology 53: 1020-1022, 2011.

5. Hanahan D and Weinberg RA: Hallmarks of cancer: The next generation. Cell 144: 646-674, 2011.

6. Ponting CP, Oliver PL and Reik W: Evolution and functions of long noncoding RNAs. Cell 136: 629-641, 2009.

7. Ulitsky I and Bartel DP: lincRNAs: Genomics, evolution, and mechanisms. Cell 154: 26-46, 2013.

8. Quinn JJ and Chang HY: Unique features of long non-coding RNA biogenesis and function. Nat Rev Genet 17: 47-62, 2016.

9. Gutschner T, Hämmerle M, Eissmann M, Hsu J, Kim Y, Hung G, Revenko A, Arun G, Stentrup M, Gross M, et al: The noncoding RNA MALAT1 is a critical regulator of the metastasis phenotype of lung cancer cells. Cancer Res 73: 1180-1189, 2013.

10. Panzitt K, Tschernatsch MM, Guelly C, Moustafa T, Stradner M, Strohmaier HM, Buck CR, Denk H, Schroeder R, Trauner M and Zatloukal K: Characterization of HULC, a novel gene with striking up-regulation in hepatocellular carcinoma, as noncoding RNA. Gastroenterology 132: 330-342, 2007.

11. Nissan A, Stojadinovic A, Mitrani-Rosenbaum S, Halle D, Grinbaum R, Roistacher M, Bochem A, Dayanc BE, Ritter G, Gomceli I, et al: Colon cancer associated transcript-1: A novel RNA expressed in malignant and pre-malignant human tissues. Int J Cancer 130: 1598-1606, 2012.

12. Huarte M: The emerging role of lncRNAs in cancer. Nat Med 21: 1253-1261, 2015.

13. Wang Y, Chen F, Zhao M, Yang Z, Li J, Zhang S, Zhang W, Ye $L$ and Zhang $X$ : The long noncoding RNA HULC promotes liver cancer by increasing the expression of the HMGA2 oncogene via sequestration of the microRNA-186. J Biol Chem 292: 15395-15407, 2017.

14. He JH, Han ZP, Liu JM, Zhou JB, Zou MX, Lv YB, Li YG and Cao MR: Overexpression of long non-coding RNA MEG3 inhibits proliferation of hepatocellular carcinoma Huh7 cells via negative modulation of miRNA-664. J Cell Biochem 118: 3713-3721, 2017.

15. He Y, Meng XM, Huang C, Wu BM, Zhang L, Lv XW and Li J: Long noncoding RNAs: Novel insights into hepatocelluar carcinoma. Cancer Letters 344: 20-27, 2014.

16. Gong X, Wei W, Chen L, Xia Z and Yu C: Comprehensive analysis of long non-coding RNA expression profiles in hepatitis B virus-related hepatocellular carcinoma. Oncotarget 7: 42422-42430, 2016.

17. Yang Y, Chen L, Gu J, Zhang H, Yuan J, Lian Q, Lv G, Wang S, Wu Y, Yang YT, et al: Recurrently deregulated lncRNAs in hepatocellular carcinoma. Nat Commun 8: 14421, 2017.

18. Li D, Liu X, Zhou J, Hu J, Zhang D, Liu J, Qiao Y and Zhan Q: Long noncoding RNA HULC modulates the phosphorylation of YB-1 through serving as a scaffold of extracellular signal-regulated kinase and YB-1 to enhance hepatocarcinogenesis. Hepatology 65: 1612-1627, 2017. 
19. He T, Zhang L, Kong Y, Huang Y, Zhang Y, Zhou D, Zhou X, Yan Y, Zhang L, Lu S, et al: Long non-coding RNA CASC15 is upregulated in hepatocellular carcinoma and facilitates hepatocarcinogenesis. Int J Oncol 51: 1722-1730, 2017.

20. Du Y, Kong G, You X, Zhang S, Zhang T, Gao Y, Ye L and Zhang X: Elevation of highly up-regulated in liver cancer (HULC) by hepatitis B virus $\mathrm{X}$ protein promotes hepatoma cell proliferation via down-regulating p18. J Biol Chem 287: 26302-26311, 2012.

21. Quagliata L,Matter MS,Piscuoglio S, Arabi L, Ruiz C,Procino A, Kovac M, Moretti F, Makowska Z, Boldanova T, et al: Long noncoding RNA HOTTIP/HOXA13 expression is associated with disease progression and predicts outcome in hepatocellular carcinoma patients. Hepatology 59: 911-923, 2014.

22. Li SP, Xu HX, Yu Y, He JD, Wang Z, Xu YJ, Wang CY, Zhang HM, Zhang RX, Zhang JJ, et al: lncRNA HULC enhances epithelial-mesenchymal transition to promote tumorigenesis and metastasis of hepatocellular carcinoma via the miR-200a-3p/ZEB1 signaling pathway. Oncotarget 7: 42431-42446, 2016.

23. Cui M, Xiao Z, Wang Y, Zheng M, Song T, Cai X, Sun B, Ye L and Zhang X: Long noncoding RNA HULC modulates abnormal lipid metabolism in hepatoma cells through an miR-9-mediated RXRA signaling pathway. Cancer Res 75: 846-857, 2015.

24. Lu Z, Xiao Z, Liu F, Cui M, Li W, Yang Z, Li J, Ye L and Zhang X: Long non-coding RNA HULC promotes tumor angiogenesis in liver cancer by up-regulating sphingosine kinase 1 (SPHK1) Oncotarget 7: 241-254, 2016.

25. Yu X, Zheng H, Chan MT and Wu WK: HULC: An oncogenic long non-coding RNA in human cancer. J Cell Mol Med 21: 410-417, 2017.

26. Braconi C, Kogure T, Valeri N, Huang N, Nuovo G, Costinean S, Negrini M, Miotto E, Croce CM and Patel T: microRNA-29 can regulate expression of the long non-coding RNA gene MEG3 in hepatocellular cancer. Oncogene 30: 4750-4756, 2011

27. Zhu J, Liu S, Ye F, Shen Y, Tie Y, Zhu J, Wei L, Jin Y, Fu H, Wu Y and Zheng X: Long noncoding RNA MEG3 interacts with p53 protein and regulates partial p53 target genes in hepatoma cells. PLoS One 10: e0139790, 2015.

28. Thiery JP, Acloque H, Huang RY and Nieto MA Epithelial-mesenchymal transitions in development and disease. Cell 139: 871-890, 2009.

29. Moreno-Bueno G, Portillo F and Cano A: Transcriptional regulation of cell polarity in EMT and cancer. Oncogene 27: 6958-6969, 2008

30. Yilmaz M and Christofori G: EMT, the cytoskeleton, and cancer cell invasion. Cancer Metastasis Rev 28: 15-33, 2009.

31. Peinado H, Olmeda D and Cano A: Snail, Zeb and bHLH factors in tumour progression: An alliance against the epithelial phenotype? Nat Rev Cancer 7: 415-428, 2007.

32. De Craene B and Berx G: Regulatory networks defining EMT during cancer initiation and progression. Nat Rev Cancer 13: 97-110, 2013

33. Lee JT: Epigenetic regulation by long noncoding RNAs Science 338: 1435-1439, 2012.

34. Nieto MA, Huang RY, Jackson RA and Thiery JP: Emt: 2016. Cell 166: 21-45, 2016.

35. Yuan JH, Yang F, Wang F, Ma JZ, Guo YJ, Tao QF, Liu F, Pan W, Wang TT, Zhou CC, et al: A long noncoding RNA activated by TGF-beta promotes the invasion-metastasis cascade in hepatocellular carcinoma. Cancer Cell 25: 666-681, 2014.

36. Zhou N, Si Z, Li T, Chen G, Zhang Z and Qi H: Long non-coding RNA CCAT2 functions as an oncogene in hepatocellular carcinoma, regulating cellular proliferation, migration and apoptosis. Oncol Lett 12: 132-138, 2016

37. Xu Y, Wang B, Zhang F, Wang A, Du X, Hu P, Zhu Y and Fang Z: Long non-coding RNA CCAT2 is associated with poor prognosis in hepatocellular carcinoma and promotes tumor metastasis by regulating Snail2-mediated epithelial-mesenchymal transition. Onco Targets Ther 10: 1191-1198, 2017.

38. Chen F, Bai G, Li Y, Feng Y and Wang L: A positive feedback loop of long noncoding RNA CCAT2 and FOXM1 promotes hepatocellular carcinoma growth. Am J Cancer Res 7: 1423-1434, 2017.

39. Liu J, Lu C, Xiao M, Jiang F, Qu L and Ni R: Long non-coding RNA SNHG20 predicts a poor prognosis for HCC and promotes cell invasion by regulating the epithelial-to-mesenchymal transition. Biomed Pharmacother 89: 857-863, 2017.

40. Zhou M, Zhang XY and Yu X: Overexpression of the long non-coding RNA SPRY4-IT1 promotes tumor cell proliferation and invasion by activating EZH2 in hepatocellular carcinoma. Biomed Pharmacother 85: 348-354, 2017.
41. Xiao JN, Yan TH, Yu RM, Gao Y, Zeng WL, Lu SW, Que HX, Liu ZP and Jiang JH: Long non-coding RNA UCA1 regulates the expression of Snail2 by miR-203 to promote hepatocellular carcinoma progression. J Cancer Res Clin Oncol 143: 981-990, 2017.

42. Zhang Y,Li Z, Zhang Y,Zhong Q, Chen Q and Zhang L: Molecular mechanism of HEIH and HULC in the proliferation and invasion of hepatoma cells. Int J Clin Exp Med 8: 12956-12962, 2015.

43. Cao SW, Huang JL, Chen J, Hu YW, Hu XM, Ren TY, Zheng SH, Lin JD, Tang J, Zheng L and Wang Q: Long non-coding RNA UBE2CP3 promotes tumor metastasis by inducing epithelial-mesenchymal transition in hepatocellular carcinoma. Oncotarget 8: 65370-65385, 2017.

44. Yan X, Zhang D, Wu W, Wu S, Qian J, Hao Y, Yan F, Zhu P, Wu J, Huang G, et al: Mesenchymal stem cells promote hepatocarcinogenesis via lncRNA-MUF interaction with ANXA2 and miR-34a. Cancer Res 77: 6704-6716, 2017.

45. Lv J, Fan HX, Zhao XP, Lv P, Fan JY, Zhang Y, Liu M and Tang H: Long non-coding RNA Unigene 56159 promotes epithelial-mesenchymal transition by acting as a ceRNA of miR-140-5p in hepatocellular carcinoma cells. Cancer Lett 382: $166-175,2016$.

46. Gou X, Zhao X and Wang Z: Long noncoding RNA PVT1 promotes hepatocellular carcinoma progression through regulating miR-214. Cancer Biomark 20: 511-519, 2017.

47. Ding G, Peng Z, Shang J, Kang Y, Ning $\mathrm{H}$ and Mao C: LincRNA-p21 inhibits invasion and metastasis of hepatocellular carcinoma through miR-9/E-cadherin cascade signaling pathway molecular mechanism. Onco Targets Ther 10: 3241-3247, 2017.

48. Lan T, Chang L, Wu L and Yuan Y: Downregulation of ZEB2-AS1 decreased tumor growth and metastasis in hepatocellular carcinoma. Mol Med Rep 14: 4606-4612, 2016.

49. Huang JF, Guo YJ, Zhao CX, Yuan SX, Wang Y, Tang GN, Zhou WP and Sun SH: Hepatitis B virus X protein (HBx)-related long noncoding RNA (lncRNA) down-regulated expression by HBx (Dreh) inhibits hepatocellular carcinoma metastasis by targeting the intermediate filament protein vimentin. Hepatology 57: 1882-1892, 2013.

50. Wang TH, Lin YS, Chen Y, Yeh CT, Huang YL, Hsieh TH, Shieh TM, Hsueh C and Chen TC: Long non-coding RNA AOC4P suppresses hepatocellular carcinoma metastasis by enhancing vimentin degradation and inhibiting epithelial-mesenchymal transition. Oncotarget 6: 23342-23357, 2015.

51. Chang L, Li C, Lan T, Wu L, Yuan Y, Liu Q and Liu Z: Decreased expression of long non-coding RNA GAS5 indicates a poor prognosis and promotes cell proliferation and invasion in hepatocellular carcinoma by regulating vimentin. Mol Med Rep 13: 1541-1550, 2016.

52. Wang Y, Liu Z, Yao B, Li Q, Wang L, Wang C, Dou C, Xu M, Liu Q and Tu K: Long non-coding RNA CASC2 suppresses epithelial-mesenchymal transition of hepatocellular carcinoma cells through CASC2/miR-367/FBXW7 axis. Mol Cancer 16: 123, 2017.

53. Lamouille S, Xu J and Derynck R: Molecular mechanisms of epithelial-mesenchymal transition. Nat Rev Mol Cell Biol 15: 178-196, 2014.

54. Li Q, Zhang C, Chen R, Xiong H, Qiu F, Liu S, Zhang M, Wang F, Wang Y, Zhou X, et al: Disrupting MALAT1/miR-200c sponge decreases invasion and migration in endometrioid endometrial carcinoma. Cancer Lett 383: 28-40, 2016.

55. Lu W, Zhang H, Niu Y, Wu Y, Sun W, Li H, Kong J, Ding K, Shen HM, Wu H, et al: Long non-coding RNA linc00673 regulated non-small cell lung cancer proliferation, migration, invasion and epithelial mesenchymal transition by sponging miR-150-5p. Mol Cancer 16: 118, 2017.

56. Rodriguez-Mateo C, Torres B, Gutierrez G and Pintor-Toro JA: Downregulation of Lnc-Spryl mediates TGF-beta-induced epithelial-mesenchymal transition by transcriptional and posttranscriptional regulatory mechanisms. Cell Death Differ 24: 785-797, 2017.

57. Li Z, Dong M, Fan D, Hou P, Li H, Liu L, Lin C, Liu J, Su L, Wu L, et al: IncRNA ANCR down-regulation promotes TGF-beta-induced EMT and metastasis in breast cancer. Oncotarget 8: 67329-67343, 2017.

58. Wang Q, Yang L, Hu X, Jiang Y, Hu Y, Liu Z, Liu J, Wen T, Ma Y, An $G$ and Feng G: Upregulated NNT-AS1, a long noncoding RNA, contributes to proliferation and migration of colorectal cancer cells in vitro and in vivo. Oncotarget 8: 3441-3453, 2017.

59. Pan H, Jiang T, Cheng N, Wang Q, Ren S, Li X, Zhao C, Zhang L, Cai W and Zhou C: Long non-coding RNA BC087858 induces non-T790M mutation acquired resistance to EGFR-TKIs by activating PI3K/AKT and MEK/ERK pathways and EMT in non-small-cell lung cancer. Oncotarget 7: 49948-49960, 2016. 
60. Jia M, Jiang L, Wang YD, Huang JZ, Yu M and Xue HZ: lincRNA-p21 inhibits invasion and metastasis of hepatocellular carcinoma through Notch signaling-induced epithelial-mesenchymal transition. Hepatol Res 46: 1137-1144, 2016.

61. Gao K, Ji Z, She K, Yang Q and Shao L: Long non-coding RNA ZFAS1 is an unfavourable prognostic factor and promotes glioma cell progression by activation of the Notch signaling pathway. Biomed Pharmacother 87: 555-560, 2017.

62. Wu J, Zhang J, Shen B, Yin K, Xu J, Gao W and Zhang L: Long noncoding RNA lncTCF7, induced by IL-6/STAT3 transactivation, promotes hepatocellular carcinoma aggressiveness through epithelial-mesenchymal transition. J Exp Clin Cancer Res 34: 116, 2015.

63. Wang TH, Yu CC, Lin YS, Chen TC, Yeh CT, Liang KH, Shieh TM, Chen CY and Hsueh C: Long noncoding RNA CPS1-IT1 suppresses the metastasis of hepatocellular carcinoma by regulating HIF-1alpha activity and inhibiting epithelial-mesenchymal transition. Oncotarget 7: 43588-43603, 2016.

64. Hong Q, Li O, Zheng W, Xiao WZ, Zhang L, Wu D, Cai GY, He JC and Chen XM: lncRNA HOTAIR regulates HIF-1alpha/AXL signaling through inhibition of miR-217 in renal cell carcinoma. Cell Death Dis 8: e2772, 2017.

65. Gupta RA, Shah N, Wang KC, Kim J, Horlings HM, Wong DJ, Tsai MC, Hung T, Argani P, Rinn JL, et al: Long non-coding RNA HOTAIR reprograms chromatin state to promote cancer metastasis. Nature 464: 1071-1076, 2010.

66. Geng YJ, Xie SL, Li Q, Ma J and Wang GY: Large intervening non-coding RNA HOTAIR is associated with hepatocellular carcinoma progression. J Int Med Res 39: 2119-2128, 2011.

67. Wang H, Huo XS, Yang XR, He J, Cheng L, Wang N, Deng X, Jin $\mathrm{H}$, Wang N, Wang C, et al: STAT3-mediated upregulation of lncRNA HOXD-AS1 as a ceRNA facilitates liver cancer metastasis by regulating SOX4. Molecular Cancer 16: 136, 2017.

68. Lu S, Zhou J, Sun Y, Li N, Miao M, Jiao B and Chen H: The noncoding RNA HOXD-AS1 is a critical regulator of the metastasis and apoptosis phenotype in human hepatocellular carcinoma. Molecular Cancer 16: 125, 2017.

69. Malakar P, Shilo A, Mogilevsky A, Stein I, Pikarsky E, Nevo Y, Benyamini H, Elgavish S, Zong X, Prasanth KV and Karni R: Long noncoding RNA MALAT1 promotes hepatocellular carcinoma development by SRSF1 upregulation and mTOR activation. Cancer Research 77: 1155-1167, 2017.

70. Hou Z, Xu X, Fu X, Tao S, Zhou J, Liu S and Tan D: HBx-related long non-coding RNA MALAT1 promotes cell metastasis via up-regulating LTBP3 in hepatocellular carcinoma. Am J Cancer Res 7: 845-856, 2017

71. Liu DL, Zhu Y, Pang JK, Weng X, Feng XR and Guo YB Knockdown of long non-coding RNA MALAT1 inhibits growth and motility of human hepatoma cells via modulation of miR-195. J Cell Biochem 119: 1368-1380, 2018.

72. Chen LS, Yao HB, Wang K and Liu XF: Long non-coding RNA MALAT1 regulates ZEB1 expression by sponging miR-143-3p and promotes hepatocellular carcinoma progression. J Cell Biochem 118: 4836-4843, 2017.

73. Li C, Miao R, Liu S, Wan Y, Zhang S, Deng Y, Bi J, Qu K, Zhang J and Liu C: Down-regulation of miR-146b-5p by long noncoding RNA MALAT1 in hepatocellular carcinoma promotes cancer growth and metastasis. Oncotarget 8: 28683-28695, 2017.

74. Fan Y, Shen B, Tan M, Mu X, Qin Y, Zhang F and Liu Y: TGF- $\beta$-induced upregulation of malat 1 promotes bladder cancer metastasis by associating with suz12. Clin Cancer Res 20 $1531-1541,2014$

75. Sun HB, Lin DC, Cao Q, Pang B, Gae DD, Lee VKM, Lim HJ, Doan N, Said JW, Gery S, et al: Identification of a nove SYK/c-MYC/MALAT1 signaling pathway and its potential therapeutic value in Ewing sarcoma. Clin Cancer Res 23: 4376-4387, 2017

76. Yuan P, Cao WB, Zang QL, Li GX, Guo XF and Fan JH: The HIF-2 alpha-MALAT1-miR-216b axis regulates multi-drug resistance of hepatocellular carcinoma cells via modulating autophagy. Biochem Bioph Res Commun 478: 1067-1073, 2016.

77. Yang F, Zhang L, Huo XS, Yuan JH, Xu D, Yuan SX, Zhu N, Zhou WP, Yang GS, Wang YZ, et al: Long noncoding RNA high expression in hepatocellular carcinoma facilitates tumor growth through enhancer of Zeste Homolog 2 in humans. Hepatology 54 1679-1689, 2011

78. Yuan SX, Yang F, Yang Y, Tao QF, Zhang J, Huang G, Yang Y, Wang RY, Yang S, Huo XS, et al: Long noncoding RNA associated with microvascular invasion in hepatocellular carcinoma promotes angiogenesis and serves as a predictor for hepatocellular carcinoma patients' poor recurrence-free survival after hepatectomy. Hepatology 56: 2231-2241, 2012.
79. Li T, Xie J, Shen C, Cheng D, Shi Y, Wu Z, Deng X, Chen H, Shen B, Peng C, et al: Upregulation of long noncoding RNA ZEB1-AS1 promotes tumor metastasis and predicts poor prognosis in hepatocellular carcinoma. Oncogene 35: 1575-1584, 2016.

80. Ren YL, Shang JH, Li JL, Liu W, Zhang Z, Yuan J and Yang M: The long noncoding RNA PCAT-1 links the microRNA miR-215 to oncogene CRKL-mediated signaling in hepatocellular carcinoma. J Biol Chem 292: 17939-17949, 2017.

81. Yang F, Huo XS, Yuan SX, Zhang L, Zhou WP, Wang F and Sun SH: Repression of the long noncoding RNA-LET by histone deacetylase 3 contributes to hypoxia-mediated metastasis. Mol Cell 49: 1083-1096, 2013

82. Wang M, Guo C, Wang L, Luo G, Huang C, Li Y, Liu D, Zeng F, Jiang $\mathrm{G}$ and $\mathrm{Xiao} \mathrm{X}$ : Long noncoding RNA GAS5 promotes bladder cancer cells apoptosis through inhibiting EZH2 transcription. Cell Death Dis 9: 238, 2018.

83. Zhang Z, Zhu Z, Watabe K, Zhang X, Bai C, Xu M, Wu F and Mo YY: Negative regulation of lncRNA GAS5 by miR-21. Cell Death Differ 20: 1558-1568, 2013.

84. Zhao XH, Wang P, Liu J, Zheng J, Liu Y, Chen J and Xue Y: Gas5 exerts tumor-suppressive functions in human glioma cells by targeting miR-222. Mol Ther 23: 1899-1911, 2015 .

85. Liu F, Yuan JH, Huang JF, Yang F, Wang TT, Ma JZ, Zhang L, Zhou CC, Wang F, Yu J, et al: Long noncoding RNA FTX inhibits hepatocellular carcinoma proliferation and metastasis by binding MCM2 and miR-374a. Oncogene 35: 5422-5434, 2016.

86. Furlan G, Gutierrez Hernandez N, Huret C, Galupa R, van Bemmel JG, Romito A, Heard E, Morey $\mathrm{C}$ and Rougeulle C: The Ftx noncoding locus controls $\mathrm{X}$ chromosome inactivation independently of its RNA products. Mol Cell 70: 462-472.e8, 2018

87. Zhuang LK, Yang YT, Ma X, Han B, Wang ZS, Zhao QY, Wu LQ and Qu ZQ: MicroRNA-92b promotes hepatocellular carcinoma progression by targeting Smad7 and is mediated by long non-coding RNA XIST. Cell Death Dis 7: e2203, 2016.

88. Chang SZ, Chen BH, Wang XY, Wu KQ and Sun YQ: Long non-coding RNA XIST regulates PTEN expression by sponging miR-181a and promotes hepatocellular carcinoma progression. BMC Cancer 17: 248, 2017.

89. Kong Q, Zhang S, Liang C, Zhang Y, Kong Q, Chen S, Qin J and Jin Y: lncRNA XIST functions as a molecular sponge of miR-194-5p to regulate MAPK1 expression in hepatocellular carcinoma cell. J Cell Biochem 119: 4458-4468, 2018.

90. Ma L, Zhou YJ, Luo XJ, Gao H, Deng XB and Jiang YJ: Long non-coding RNA XIST promotes cell growth and invasion through regulating miR-497/MACC1 axis in gastric cancer. Oncotarget 8: 4125-4135, 2017.

91. Chen DL, Chen LZ, Lu YX, Zhang DS, Zeng ZL, Pan ZZ, Huang P, Wang FH, Li YH, Ju HQ and Xu RH: Long noncoding RNA XIST expedites metastasis and modulates epithelial-mesenchymal transition in colorectal cancer. Cell Death Dis 8: e3011, 2017.

92. Wu XL, Dinglin XX, Wang X, Luo W, Shen Q, Li Y, Gu L, Zhou Q, Zhu H, Li Y, et al: Long noncoding RNA XIST promotes malignancies of esophageal squamous cell carcinoma via regulation of miR-101/EZH2. Oncotarget 8: 76015-76028, 2017.

93. Gramantieri L, Fornari F, Callegari E, Sabbioni S, Lanza G, Croce CM, Bolondi L and Negrini M: MicroRNA involvement in hepatocellular carcinoma. J Cell Mol Med 12: 2189-2204, 2008.

94. Schmitt M, Horbach A, Kubitz R, Frilling A and Häussinger D: Disruption of hepatocellular tight junctions by vascular endothelial growth factor (VEGF): A novel mechanism for tumor invasion. J Hepatol 41: 274-283, 2004.

95. Choi SB, Han HJ, Kim WB, Song TJ and Choi SY: VEGF overexpression predicts poor survival in hepatocellular carcinoma. Open Med (Wars) 12: 430-439, 2017

96. Cao G, Li X, Qin C and Li J: Prognostic value of VEGF in hepatocellular carcinoma patients treated with Sorafenib: A meta-analysis. Med Sci Monit 21: 3144-3151, 2015.

97. Fu WM, Lu YF, Hu BG, Liang WC, Zhu X, Yang HD, Li G and Zhang JF: Long noncoding RNA Hotair mediated angiogenesis in nasopharyngeal carcinoma by direct and indirect signaling pathways. Oncotarget 7: 4712-4723, 2016

98. Ma X, Li Z, Li T, Zhu L, Li Z and Tian N: Long non-coding RNA HOTAIR enhances angiogenesis by induction of VEGFA expression in glioma cells and transmission to endothelial cells via glioma cell derived-extracellular vesicles. Am J Transl Res 9: 5012-5021, 2017.

99. Su W, Xie W, Shang Q and Su B: The long noncoding RNA MEG3 is downregulated and inversely associated with vegf levels in osteoarthritis. Biomed Res Int 2015: 356893, 2015. 
100.Zhan R, Xu K, Pan J, Xu Q, Xu S and Shen J: Long noncoding RNA MEG3 mediated angiogenesis after cerebral infarction through regulating p53/NOX4 axis. Biochem Biophys Res Commun 490: 700-706, 2017.

101. Liu L, Chen X, Zhang Y, Hu Y, Shen X and Zhu W: Long non-coding RNA TUG1 promotes endometrial cancer development via inhibiting miR-299 and miR-34a-5p. Oncotarget 8: 31386-31394, 2017.

102. Jiang Q, Shan K, Qun-Wang X, Zhou RM, Yang H, Liu C, Li YJ, Yao J, Li XM, Shen Y, et al: Long non-coding RNA-MIAT promotes neurovascular remodeling in the eye and brain. Oncotarget 7: 49688-49698, 2016.

103. Li X, Song Y, Liu F, Liu D, Miao H, Ren J, Xu J, Ding L, Hu Y Wang Z, et al: Long non-coding RNA MALAT1 promotes proliferation, angiogenesis, and immunosuppressive properties of mesenchymal stem cells by inducing VEGF and IDO. J Cell Biochem 118: 2780-2791, 2017.

104. Zhu Y, Zhang X, Qi L, Cai Y, Yang P, Xuan G and Jiang Y: HULC long noncoding RNA silencing suppresses angiogenesis by regulating ESM-1 via the PI3K/Akt/mTOR signaling pathway in human gliomas. Oncotarget 7: 14429-14440, 2016.

105. Xiao H, Tong R, Cheng S, Lv Z, Ding C, Du C, Xie H, Zhou L, Wu $\mathrm{J}$ and Zheng S: BAG3 and HIF-1 alpha coexpression detected by immunohistochemistry correlated with prognosis in hepatocellular carcinoma after liver transplantation. Biomed Res Int 2014: 516518, 2014.
106. Takahashi K, Yan IK, Haga H and Patel T: Modulation of hypoxia-signaling pathways by extracellular linc-RoR. J Cell Sci 127: 1585-1594, 2014.

107. Zhuang J, Shen L, Yang L, Huang X, Lu Q, Cui Y, Zheng X, Zhao X, Zhang D, Huang R, et al: TGF $\beta 1$ promotes gemcitabine resistance through regulating the lncRNA-LET/NF90/miR-145 signaling axis in bladder cancer. Theranostics 7: 3053-3067, 2017.

108. Zhu Z, Gao X, He Y, Zhao H, Yu Q, Jiang D, Zhang P, Ma X Huang H, Dong D, et al: An insertion/deletion polymorphism within RERT-lncRNA modulates hepatocellular carcinoma risk. Cancer Res 72: 6163-6172, 2012.

109. Mineo M, Ricklefs F, Rooj AK, Lyons SM, Ivanov P, Ansari KI, Nakano I, Chiocca EA, Godlewski J and Bronisz A: The long non-coding RNA HIF1A-AS2 facilitates the maintenance of mesenchymal glioblastoma stem-like cells in hypoxic Niches. Cell Rep 15: 2500-2509, 2016.

110. Wang J, Chen L, Li H, Yang J, Gong Z, Wang B and Zhao X: Clopidogrel reduces apoptosis and promotes proliferation of human vascular endothelial cells induced by palmitic acid via suppression of the long non-coding RNA HIF1A-AS1 in vitro. Mol Cell Biochem 404: 203-210, 2015.

This work is licensed under a Creative Commons Attribution-NonCommercial-NoDerivatives 4.0 International (CC BY-NC-ND 4.0) License. 